\title{
Article \\ Nanosheets with High-Performance Electrochemical Oxygen Reduction Reaction Revived from Green Walnut Peel
}

\author{
Yifei Zhou ${ }^{1}$, Lei Yan ${ }^{1}$ and Junhua Hou ${ }^{1,2,3, *(D)}$ \\ 1 School of Physics and Information Engineering, Shanxi Normal University, No. 339 Taiyu Road, \\ Xiaodian District, Taiyuan 030031, China; 219110014@sxnu.edu.cn (Y.Z.); 220110010@sxnu.edu.cn (L.Y.) \\ 2 Extreme Optical Collaborative Innovation Center, Shanxi University, No. 92, Wucheng Road, \\ Xiaodian District, Taiyuan 030006, China \\ 3 Modern College of Humanities and Sciences, Shanxi Normal University, No. 501 Binhe West Road, \\ Yaodu District, Linfen 041000, China \\ * Correspondence: jhhou@sxnu.edu.cn; Tel.: +86-13203574868
}

check for updates

Citation: Zhou, Y.; Yan, L.; Hou, J. Nanosheets with High-Performance Electrochemical Oxygen Reduction Reaction Revived from Green Walnut Peel. Molecules 2022, 27, 328.

https://doi.org/10.3390/molecules 27010328

Academic Editor: Dipendu Saha

Received: 10 December 2021

Accepted: 28 December 2021

Published: 5 January 2022

Publisher's Note: MDPI stays neutral with regard to jurisdictional claims in published maps and institutional affiliations.

Copyright: (c) 2022 by the authors. Licensee MDPI, Basel, Switzerland. This article is an open access article distributed under the terms and conditions of the Creative Commons Attribution (CC BY) license (https:// creativecommons.org/licenses/by/ $4.0 /)$.

\begin{abstract}
The synthesis of metal-free carbon-based electrocatalysts for oxygen reduction reactions (ORR) to replace conventional Pt-based catalysts has become a hot spot in current research. This work proposes an activation-assisted carbonization strategy, to manufacture N-doped ultra-thin carbon nanosheets (GWS180M800) with high catalytic activity, namely, melamine is used as an accelerator/nitrogen source, and walnut green peels biological waste as a carbon source. The melamine acts as a nitrogen donor in the hydrothermal process, effectively enhancing the nitrogen doping rate. The content of pyridine nitrogen groups accounts for up to $48.5 \%$ of the total nitrogen content. Electrochemical tests show that the GWS180M800 has excellent ORR electrocatalytic activity and stability, and makes a quasi-four-electron ORR pathway clear in the alkaline electrolyte. The initial potential and half slope potential are as high as 1.01 and $0.82 \mathrm{~V}$ vs. RHE, respectively. The GWS180M800 catalyst has a better ability to avoid methanol cross poisoning than $\mathrm{Pt} / \mathrm{C}$ has. Compared with $20 \mathrm{wt} \% \mathrm{Pt} / \mathrm{C}$, GWS180M800 has improved methanol tolerance and stability. It is a metal-free biochar ORR catalyst with great development potential and application prospects. This result provides a new space for the preparation of valuable porous nano-carbon materials based on carbonaceous solid waste and provides new ideas for catalyzing a wide range of electrochemical reactions in the future.
\end{abstract}

Keywords: biomass carbon; oxygen reduction reaction; N-doped; catalyst; methanol tolerance; stability

\section{Introduction}

With the gradual intensification of global energy and environmental issues, the development and utilization of clean energy have become an inevitable development trend. Fuel cells are considered to be a promising and effective alternative due to their clean, stable, and sustainable characteristics [1-4]. However, the excessively high overpotential and slow kinetics of the cathode inhibited its large-scale development. In addition, $\mathrm{Pt}$ and catalysts, which are considered to have the best catalytic activity, greatly limit their commercial development due to their limited reserves, high prices, susceptibility to methanol cross-effects, and CO poisoning, and poor tolerance [5-7]. As a result, it is very important to accelerate the ORR reaction rate and improve the energy conversion efficiency of the battery for developing new energy sources and protecting the environment [8].

Studies have shown that the oxygen reduction electrocatalyst prepared from biomassderived materials, such as activated carbon [9], enzymes [10], microorganisms [11], and transition metal porphyrin [12], solid organic waste extract [13], has the characteristics of green and easy availability, superior performance, high stability, and high activity, and it has the potential to replace precious-metal-based ORR catalysts [14-17]. Consequently, biomass-derived materials have drawn great attention from researchers [18-23]. 
According to public data, China's walnut output was about 3.627 million tons in 2019. In the process of walnut kernel processing, a large amount of green walnut peel is wasted because it is not effectively used. Thus, converting it into high value-added ORR catalyst products has huge environmental and economic benefits. This research will provide an easy-to-implement method to prepare a stable ORR catalyst from renewable waste green walnut hull biomass and provide an innovative strategy for the production of biomass.

In this work, a catalyst synthesis strategy with green walnut skin as the precursor, a simple preparation process, and low cost was proposed. The synthesis process includes a hydrothermal process under melamine doping and then annealing with $\mathrm{N}_{2}$. The surface morphology and structural characteristics of the catalysts are manifested by SEM, TEM, Raman, XPS, etc., and further explored the mechanism of catalyst activity improvement. The results show that after activation, a large number of organic pores are formed, a higher specific surface area, and the $\mathrm{N}$ doping rate $(10.46 \%)$ and defects have been significantly improved, which is of great significance to the improvement of catalyst activity. It is worth noting that the catalyst GWS180M800 exhibits high catalytic activity, methanol tolerance, and high stability in alkaline media. The catalyst also shows good activity against acidic ORR. This strategy converting agricultural and forestry wastes into high-value-added products is simple, low-cost, and easy to promote.

The oxygen reduction reaction in an aqueous solution can generally be carried on through the four-electron pathway and the two-electron pathway. The four-electron pathway directly reduces oxygen to water, while the two-electron pathway has hydrogen peroxide as the intermediate of the reaction. The four-electron pathway is obviously preferable to the two-electron pathway with the reaction intermediate hydrogen peroxide, and the path used for the specific catalyst depends on the type of catalyst [24].

Many articles on non-metallic catalysts have clear explanations of the neutral and alkaline reaction mechanisms of oxygen reduction reactions $[25,26]$. The reaction mechanism can be summarized as:

Four electronic paths:

$$
\mathrm{O}_{2}+2 \mathrm{H}_{2} \mathrm{O}+4 e^{-} \rightarrow 4 \mathrm{OH}^{-}
$$

Two electronic paths:

$$
\begin{aligned}
& \mathrm{O}_{2}+2 \mathrm{H}_{2} \mathrm{O}+2 e^{-} \rightarrow \mathrm{HO}_{2}^{-} \\
& \mathrm{O}_{2}^{-}+\mathrm{H}_{2} \mathrm{O}+2 e^{-} \rightarrow 3 \mathrm{OH}^{-}
\end{aligned}
$$

In an acidic medium, the mechanism can be described as follows:

Four electronic paths:

$$
\mathrm{O}_{2}+4 \mathrm{H}^{+}+4 e^{-} \rightarrow 2 \mathrm{H}_{2} \mathrm{O}
$$

Two electronic paths:

$$
\begin{aligned}
\mathrm{O}_{2}+2 \mathrm{H}^{+}+2 e^{-} & \rightarrow \mathrm{H}_{2} \mathrm{O}_{2} \\
\mathrm{H}_{2} \mathrm{O}_{2}+2 \mathrm{H}^{+} & \rightarrow 2 \mathrm{H}_{2}
\end{aligned}
$$

\section{Results and Discussion}

All electrochemical measurements are completed in electrochemical workstation (Chenhua CHI760E, Shanghai China). The test is carried out under a three-electrode system, with $0.1 \mathrm{M} \mathrm{KOH}$ aqueous solution as the electrolyte, with a catalyst-modified glass rotating disc electrode (GC-RDE) as the working electrode, and with platinum wire with $3 \mathrm{M} / \mathrm{L} \mathrm{KCl}$ solution and the $\mathrm{Ag} / \mathrm{AgCl}$ electrodes as the counter electrode and the reference electrode, respectively. Firstly, the glassy carbon electrode (GC, diameter $3 \mathrm{~mm}$ ) is polished with $0.05 \mathrm{~mm}$ Alumina powder. Secondly, use an appropriate amount of absorbent cotton dipped in a small amount of absolute ethanol to wipe the surface of the electrode clean. Then, $5 \mathrm{mg}$ of catalyst, $50 \mu \mathrm{L}$ Nafion solution, $250 \mu \mathrm{L}$ isopropanol, and $700 \mu \mathrm{L}$ deionized water are mixed in a $1.5 \mathrm{~mL}$ centrifuge tube and sonicated for $1 \mathrm{~h}$ with a sonicator to form a catalyst suspension. Finally, take $10 \mu \mathrm{L}$ droplets of the catalyst suspension on the 
surface of the electrode and wait for it to dry naturally (the average catalyst loading is $0.25 \mathrm{mg} \cdot \mathrm{cm}^{-2}$ ).

To keep the gas saturated in the solution, pass oxygen into the electrolytic cell for $30 \mathrm{~min}$ before testing. Then the ORR performance of the material was tested by cyclic voltammetry (CV) and linear sweep voltammetry (LSV).

According to the Nernst equation, the potential measured in this article is converted into a reversible hydrogen electrode (RHE) scale

$$
E_{V S . R H E}=E_{V S . A g / A g C l}+E_{V S . A g / A g C l}^{\theta}+0.059 p H\left(25^{\circ} \mathrm{C}\right)
$$

The value of the electron transfer number $(n)$ can be calculated from the slope of the linear fitting line according to the Kentucky-Levich equation:

$$
\begin{gathered}
\frac{1}{i}=\frac{1}{i_{l}}+\frac{1}{i_{k}}=\frac{1}{B \omega^{1 / 2}}+\frac{1}{i_{k}} \\
B=0.62 n F C_{0} D_{0}^{2 / 3} v^{-1 / 6}
\end{gathered}
$$

$i$ is the actual measured current density; $i_{k}$ and $i_{l}$ is the kinetic and limiting diffusion current density; $\omega$ is the angular velocity of the disk; $n$ is the total number of electrons transferred in the ORR; $F$ is the Faraday constant $\left(96,485 \mathrm{C} \mathrm{mol}^{-1}\right) ; C_{0}$ is the oxygen concentration in $0.1 \mathrm{M} \mathrm{KOH}\left(1.2 \times 10^{-6} \mathrm{~mol} \cdot \mathrm{cm}^{-3}\right) ; D_{0}$ is the diffusion coefficient of oxygen in $0.1 \mathrm{M} \mathrm{KOH}\left(1.9 \times 10^{-5} \mathrm{~cm}^{-2} \cdot \mathrm{s}^{-1}\right)$; $v$ is the dynamic viscosity of the electrolyte $\left(1.0 \times 10^{-2} \mathrm{~cm}^{2} \cdot \mathrm{s}^{-1}\right)$.

In a $0.1 \mathrm{M} \mathrm{KOH}$ solution saturated with $\mathrm{O}_{2}$, a rotating disk electrode (RRDE) was used to test the number of electron transfer and hydrogen peroxide yield of the catalyst at $1600 \mathrm{rpm}$ and a scan rate of $50 \mathrm{mV} / \mathrm{s}$. Then use the formulas below to calculate $n$ and $\mathrm{H}_{2} \mathrm{O}_{2}$ yield [27].

$$
\begin{gathered}
n=4 \times \frac{I_{d}}{I_{d}+I_{r} / N} \\
\% H O_{2}^{-}=200 \times \frac{I_{r} / N}{I_{d}+I_{r} / N}
\end{gathered}
$$

When $I_{d}$ is the disk current, $I_{r}$ is the ring current, and $N(N=0.37)$ is the current collection efficiency of the Pt ring.

The scanning electron microscope (SEM) and transmission electron microscope (TEM) images of GWS180M800 are shown in Figure 1a,b. Figure 1c,d show the SEM results of the catalysts GWS180M and GWS800, respectively. It can be seen from the SEM image that the melamine and the walnut green peel will be hydrothermally combined, and the combination will collapse to form a honeycomb porous structure during the high-temperature carbonization process. The SEM images of GWS800 and WS180M800 show a block structure, so melamine has an important influence on the formation of the porous structure of the catalyst. In addition, the TEM image further shows that the prepared WS180M800 becomes thinner, which is consistent with the result of the SEM honeycomb structure.

Raman spectroscopy is used to determine the degree of graphitization of various catalysts prepared under different conditions. The Raman spectrum is shown in Figure 2a. All samples have two significant characteristic peaks: the D peak at about $1320 \mathrm{~cm}^{-1}$ corresponds to amorphous carbon and the $G$ peak at about $1590 \mathrm{~cm}^{-1}$ corresponds to graphitized carbon. The ratio of the intensity of the D peak to the intensity of the G peak is an important index for evaluating the degree of graphitization of a material [28]. The larger the $I_{D} / I_{G}$ ratio, the lower the degree of graphitization, and the greater the degree of defects in the catalyst. It can be seen that the $I_{D} / I_{G}$ ratio of the catalyst GWS180M800 increases significantly, which is due to the formation of more defects with the introduction of melamine [29]. 

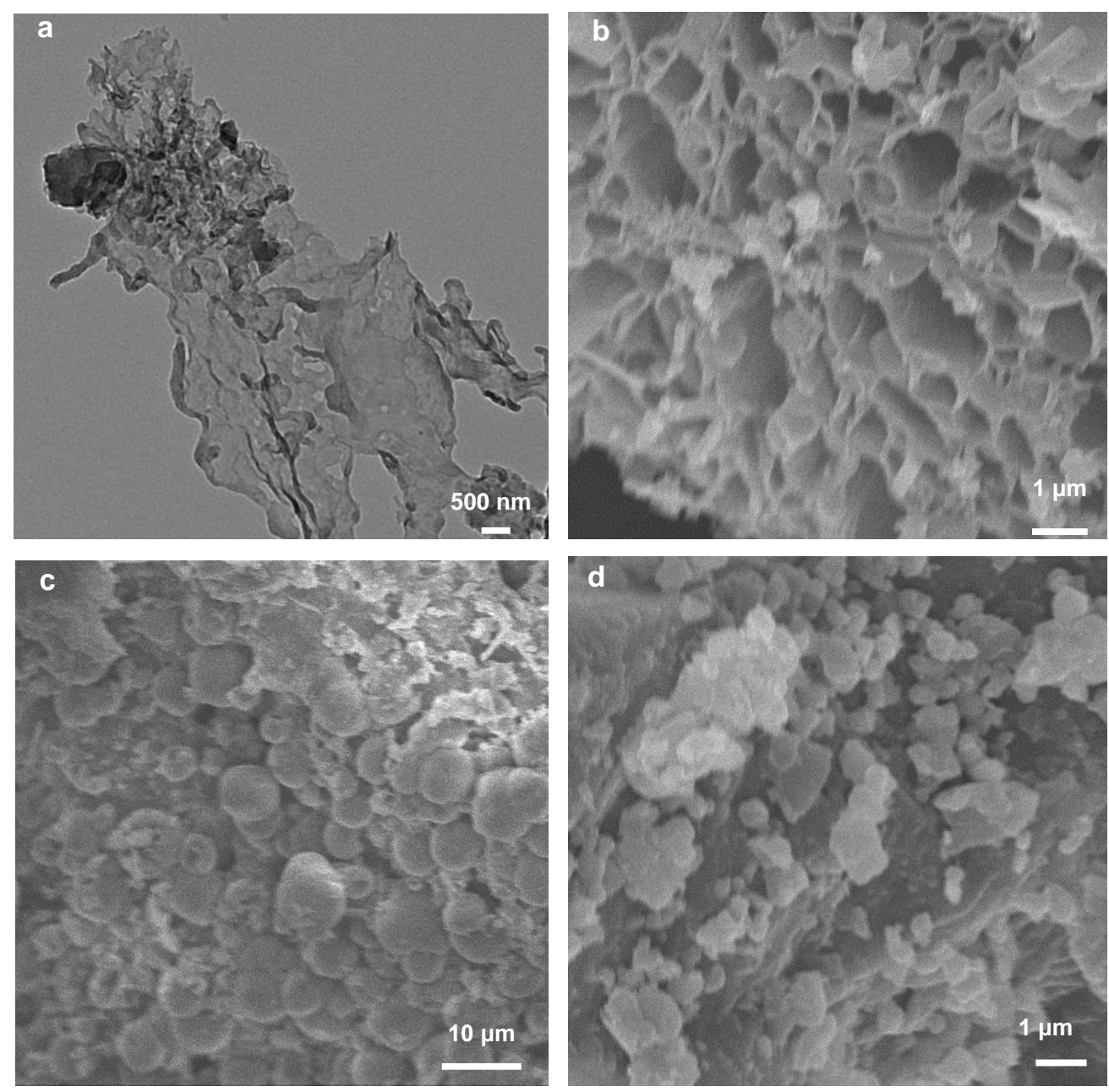

Figure 1. TEM images of GWS180M800 (a). SEM images of GWS180M800 (b), GWS180 (c), and GWS180M800 (d).

To analyze element composition and bonding configuration, we tested and analyzed the X-ray photoelectron spectroscopy (XPS) of all the GWS-X samples. In Figure $2 b$, the spectrum of GWS-X material shows three peaks. The peak centers are 285, 400, and $532 \mathrm{eV}$ respectively, corresponding to $\mathrm{C} 1 \mathrm{~s}, \mathrm{~N} 1 \mathrm{~s}$, and $\mathrm{O} 1 \mathrm{~s}$ elements [30], which shows that the obtained GWS-X sample still maintains a certain amount of nitrogen element and has an oxygen functional group. Most notably, the N content of GWS180M800 relative to GWS180 has increased significantly from $0.87 \%$ to $10.46 \%$, which has a huge effect on the improvement of its catalytic performance. To study the bonding environment of the elements, we analyze the high-resolution XPS spectra of C1s and N1s of the GWS-X series.

According to elemental analysis, the C content of GWS800, GWS180M700, GWS180M800, GWS180M900, GWS180M1000 are 81\%, 73.91\%, 70.98\%, 76.43\%, 76.43\%, and $79.18 \%$, and the $\mathrm{N}$ content is $0.87 \%, 2.11 \%, 10.46 \%, 5 \%$, and $1.28 \%$, which strongly proves that melamine acts as a nitrogen donor in the hydrothermal process, effectively enhancing the nitrogen doping rate (Table S1). Figure $2 \mathrm{~b}$ shows four characteristic peaks, located in the range of 284.15-284.58, 285.06-286.34, 286.24-287.04, and 289.19-290.18 eV, corresponding to sp ${ }^{2}$ hybridized graphitic carbon $\mathrm{C}-\mathrm{C} / \mathrm{C}=\mathrm{C}, \mathrm{C}-\mathrm{N} / \mathrm{C}=\mathrm{N}$ bond, $\mathrm{C}=\mathrm{O}$, and $\mathrm{O}-\mathrm{C}=\mathrm{O}$ bond.

Figure $2 \mathrm{c}$ is a high-resolution N1s spectrum, showing four characteristic peaks, which are located in the range of 398.10-398.84, 399.54-399.89, 400.33-400.82, and 401.39-402.15 eV [31], which are attributed to pyridine- $\mathrm{N}$, pyrrole- $\mathrm{N}$, graphite- $\mathrm{N}$, and nitric oxide bonds [32]. Furthermore, the atomic percentage of the GWS180M-X sample is quantitatively analyzed by fitting the peak area. The N content of GWS 800 is $0.87 \%$, the N content of GWS180M700 is $2.11 \%$, the N content of GWS180M800 is $10.46 \%$, the N content of GWS180M900 is 
$5 \%$, and the N content of GWS180M1000 is $1.28 \%$ (Figure 2d) [32], indicating higher pyrolysis temperature may cause the loss of nitrogen functional groups. Nevertheless, to our surprise, GWS180M800 reveals the highest nitrogen content in the honeycomb carbon structure [33-35]. After an in-depth analysis of nitrogen species (Figure 2d), in the GWS180M 700, GWS180M 800, GWS180M 900, and GWS180M1000 samples, pyridine$\mathrm{N}$ and graphite- $\mathrm{N}$ accounted for $51.31 \%, 81.9 \%, 64.5 \%$, and $13.3 \%$ of the total nitrogen components respectively. The GWS180M 800 material contains the highest nitrogen active substance in the GWS180M-X series of samples, which indicates that the catalyst may exhibit excellent electrochemical performance. Thus, the results of XPS can further explain that various $\mathrm{N}$ species have been successfully embedded in the carbon skeleton, which will produce a large number of active sites and structural defects [32,36,37].
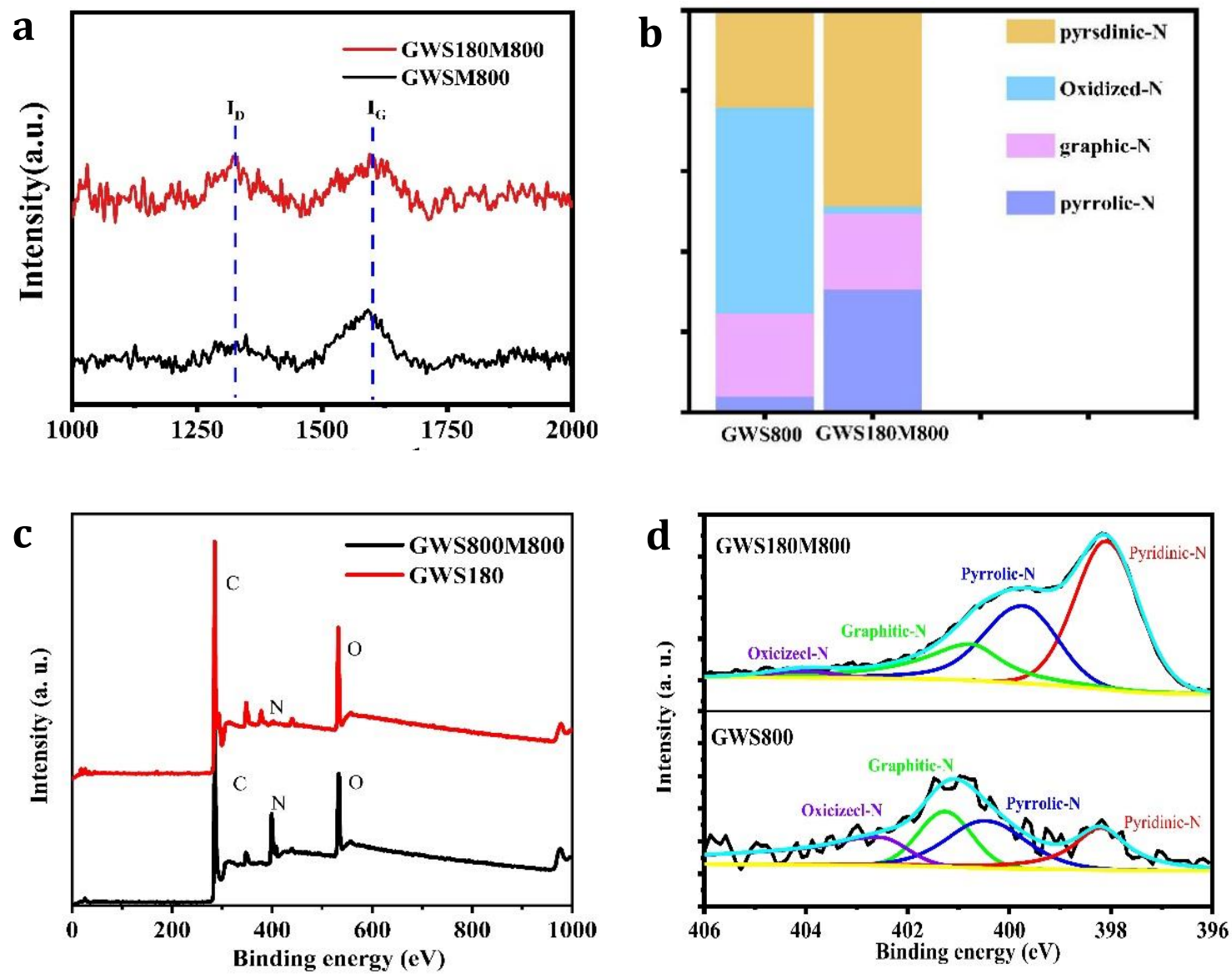

Figure 2. Raman spectra (a) of catalysts XPS spectrum (b), high-resolution XPS spectrum of N 1s (c), 3D bar graphs of the relative content of nitrogen species on the surface of GWS180M800 (d).

To evaluate the electrocatalytic activity of ORR, five carbon-based ORR catalysts are coated on the surface of the GC-RDE electrode respectively and further tested by cyclic voltammetry $(\mathrm{CV})$ and linear sweep voltammetry in a $0.1 \mathrm{M} \mathrm{KOH}$ solution saturated with $\mathrm{O}_{2}$ Method (LSV). The electrochemical results regarding ORR activity are shown in Figure 3a. It can be found that in the $\mathrm{O}_{2}$ saturated electrolyte, all the CV curves of GWS800, GWS180M700, GWS180M800, GWS180M900, GWS180M1000 show ORR peaks clearly, which can be obtained by comparing the peak potential scores of the relative RHE. The ORR activities of the five-carbon catalysts follow GWS180M800 > GWS180M900 > GWS180M700 $>$ GWS180M1000 > GWS800 in the order. What's more, the LSV curve (Figure 2b) records the saturated $\mathrm{KOH}$ solution obtained by $\mathrm{O}_{2}$ at a speed of $1600 \mathrm{rpm}$ to further understand the catalytic activity of GWS800, GWS180M700, GWS180M800, GWS180M900, and GWS180M1000. Compared with the GWS800 catalytic electrode with $E_{1 / 2}$ of $0.70 \mathrm{~V}$ with 
RHE, the electrode catalyzed by GWS180M800 shows better ORR activity when the halfwave potential $\left(\mathrm{E}_{1 / 2}\right)$ is $0.82 \mathrm{~V}$. In addition, on the GWS180M800 catalyst, the initial potential is $1.01 \mathrm{~V}$, and a higher limiting current density can be obtained, which is comparable to the commercial $\mathrm{Pt} / \mathrm{C}$ catalyst electrode $(20 \mathrm{wt} \%)$. These results are in good agreement with the results of CV measurement, and further display the excellent ORR activity of GWS180M800. Due to a large number of defects and the improvement of nitrogen doping efficiency in the pyrolysis process, the catalytic activity of ORR is improved. The high annealing temperature caused a large loss of $\mathrm{N}$ content from $10.46 \%\left(800{ }^{\circ} \mathrm{C}\right)$ to $1.28 \%\left(1000{ }^{\circ} \mathrm{C}\right)$ [38], as demonstrated by XPS. That's why the value of the limiting current density indicates GWS180M800 > GWS180M900 > GWS180M700 > GWS180M1000 > GWS800. Accordingly, finding the optimal carbonization temperature is very important for preparing carbon material samples with high ORR activity.
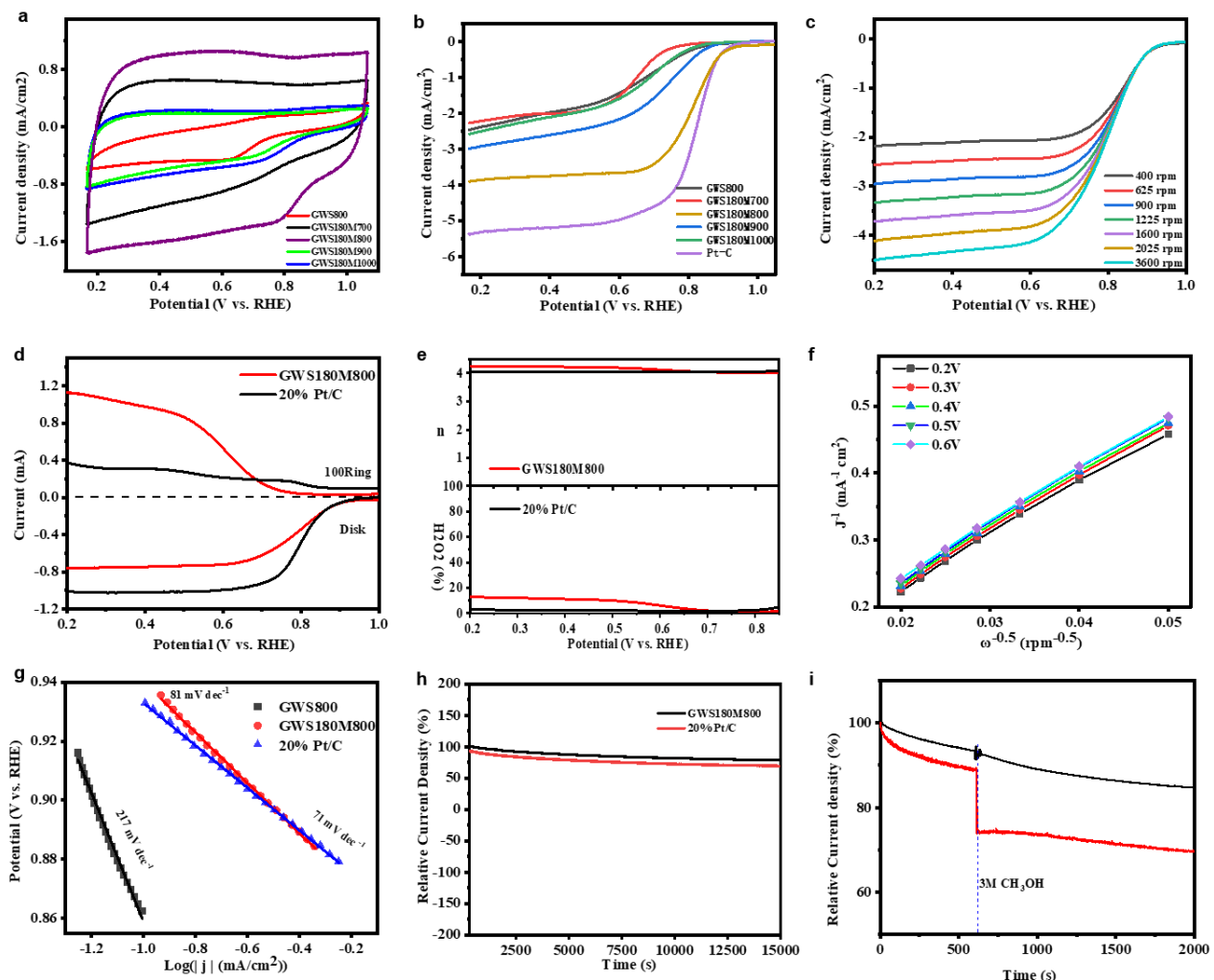

Figure 3. $\mathrm{CV}$ curves (a) of all catalysts in $\mathrm{O}_{2}$ saturated $0.1 \mathrm{M} \mathrm{KOH}$ solution at room temperature and scanning rate of $50 \mathrm{mV} / \mathrm{s}$. The LSV curves of GWS-X at an electrode rotation rate of $1600 \mathrm{rpm}$ and a scan rate of $10 \mathrm{mV} / \mathrm{s} \mathrm{(b)}$. The LSV curve (c) of GWS180M800 at different speeds from 400 to $2025 \mathrm{rpm}$ corresponds to the K-L diagram (f) GWS180M800 from 0.2 to $0.6 \mathrm{~V}$ respectively. The RRDE linear scan voltammogram of GWS180M800 and $20 \mathrm{wt} \% \mathrm{Pt} / \mathrm{C}$ in $0.1 \mathrm{M} \mathrm{KOH}$ saturated with $\mathrm{O}_{2}$, the electrode rotation rate and scan rate are $1600 \mathrm{rpm}$ and $5 \mathrm{mV} / \mathrm{s}$, respectively (d). Electron transfer number $\mathrm{n}$ (up e) and $\mathrm{H}_{2} \mathrm{O}_{2}$ yield (down e) calculated from the results of GWS180M800 and $20 \mathrm{wt} \% \mathrm{Pt} / \mathrm{C}$ RRDE measurement. Tafel slope curve spectrum (g). The stability curve of GWS180M800 and $20 \mathrm{wt} \% \mathrm{Pt} / \mathrm{C}$

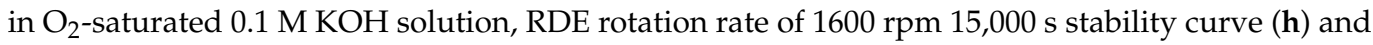
methanol measured by chronoamperometric amperometric method Tolerance performance curve (i).

Then, Tafel analysis is used to obtain kinetic information. As shown in Figure $3 g$, the Tafel slope ( $81 \mathrm{mV} \mathrm{dec}{ }^{-1}$ ) of GWS180M800 is close to the Tafel slope $\left(71 \mathrm{mV} \mathrm{dec}^{-1}\right)$ of the reference $20 \mathrm{wt} \% \mathrm{Pt} / \mathrm{C}$ ), which indicates that there is a high exchange current density at the interface between the catalyst and the electrode. It is beneficial for practical applications. GWS800 showed a large Tafel slope of $217 \mathrm{mV} \mathrm{dec}^{-1}$, indicating a poor ORR dynamic process. These results indicate that the optimal pyrolysis temperature is essential for enhancing electrochemical activity [39]. Generally, a lower annealing temperature $\left(700{ }^{\circ} \mathrm{C}\right)$ 
will lead to insufficient carbonization, which is harmful to the formation of high graphitic carbon, and a higher calcination temperature $\left(1000^{\circ} \mathrm{C}\right)$ will cause the accumulation of graphite layers to increase. Higher pyrolysis temperature will always lead to the loss of $\mathrm{N}$ content. As proven by XPS, GWS180M800 exhibits the most excellent ORR performance in terms of initial potential and limiting current density.

To further evaluate the ORR reaction mechanism, the catalyst was coated on a rotating ring disk electrode (RRDE), and the LSV curve was measured in a $0.1 \mathrm{M} \mathrm{KOH}$ solution saturated with $\mathrm{O}_{2}$. The rotation speed was from 200 to $2000 \mathrm{rpm}$. With the rotation speed increasing, the limiting current density also increases correspondingly, and the high rotation speed will cause the diffusion distance to be shortened. At the same time, the LSV curve shows that the process may be a four-electron reaction. The measurement result is shown in Figure 3d. Both GWS180M800 and $20 \mathrm{wt} \% \mathrm{Pt} / \mathrm{C}$ showed lower ring current density, indicating that less $\mathrm{H}_{2} \mathrm{O}_{2}$ was detected on the ring electrode, which means that the catalyst has higher catalytic activity. In Figure $3 \mathrm{e}$, based on the ring current and disk current data of RRDE, we calculated the electron transfer number (n) and $\mathrm{H}_{2} \mathrm{O}_{2}$ yield through formulas. GWS180M800's $\mathrm{n}$ is 3.88 3.95, and the yield of $\mathrm{H}_{2} \mathrm{O}_{2}$ in the potential range of $0.2 \sim 1.0 \mathrm{~V}$ is slightly higher than that of $20 \mathrm{wt} \% \mathrm{Pt} / \mathrm{C}$. proves that GWS180M800 is a quasi-four-electron reaction and its catalytic activity is close to $\mathrm{Pt} / \mathrm{C}$. This corresponds to the calculation result of the K-L (Figure 3f) equation $[40,41]$.

The stability of GWS180M800 and Pt/C catalysts was also tested by current-time chronograph measurement (Figure 3h) [42,43]. With time passing by, their current density has decreased. However, the descending speed of GWS180M800 is slower than that of Pt/C, as shown in Figure 3h. After the 15,000 s test, S5a, GWS180M800, and $20 \mathrm{wt} \% \mathrm{Pt} / \mathrm{C}$ still maintained $77.3 \%$ and $72.5 \%$ of the initial current respectively. It shows that GWS180M800 has more long-term stability than the $20 \mathrm{wt} \% \mathrm{Pt} / \mathrm{C}$ catalyst has.

For ORR catalysts, the actual fuel cell must consider its resistance for cross effects. As shown in Figure 3i, in the $\mathrm{O}_{2}$ saturated $\mathrm{KOH}$ solution injected with $3.0 \mathrm{M}$ methanol, a sharp oxidation current of $20 \mathrm{wt} \% \mathrm{Pt} / \mathrm{C}$ in the i-t curve is observed. Under the same conditions, the cathode of GWS180M800 changes slightly. Add $5 \mathrm{~mL}$ of anhydrous methanol to the $0.1 \mathrm{M} \mathrm{KOH}$ electrolyte saturated with $\mathrm{O}_{2}$ at $600 \mathrm{~s}$, and the currents of GWS180M800 and $20 \mathrm{wt} \% \mathrm{Pt} / \mathrm{C}$ at $2000 \mathrm{~s}$ are $80.4 \%$ and $70.1 \%$ of the initial current respectively. This clearly shows that the prepared GWS180M800 catalyst has a better ability to avoid methanol cross poisoning than $\mathrm{Pt} / \mathrm{C}$ has. Compared with $20 \mathrm{wt} \% \mathrm{Pt} / \mathrm{C}, \mathrm{GWS} 180 \mathrm{M} 800$ has improved methanol tolerance and stability. It is a metal-free biochar ORR catalyst with great development potential and application prospects.

On the basis of the above-mentioned data, the GWS180M800 are indeed highly active toward the ORR with quite positive half-wave potentials and large limiting current densities in alkaline media and outperform most of the other equivalent benchmarks and Pt-based electrocatalysts (Table 1). The material has quite high ORR catalytic performance, which is mainly due to two aspects. First, the abundant mesoporous structure can greatly improve the mass/electron transfer efficiency and provide a large number of exposed active catalytic sites. Secondly, the best $\mathrm{N}$ element doping can produce charging defects, adjust the surface polarity of the carbon skeleton, and synergistically improve the catalytic activity of ORR.

Table 1. Comparison of some advanced metal-free ORR catalysts in $0.1 \mathrm{M} \mathrm{KOH}$ electrolyte.

\begin{tabular}{cccc}
\hline Catalysts & $E_{\text {oneset }}(\boldsymbol{V}$ vs. the $R H E)$ & $E_{1 / 2}(\boldsymbol{V}$ vs. the $R H E)$ & References \\
\hline PAC-800 & $0.99 \mathrm{~V}$ & $0.82 \mathrm{~V}$ & 4 \\
TARC-N & $0.98 \mathrm{~V}$ & $0.86 \mathrm{~V}$ & 34 \\
G800-ZC-2.0 & $0.98 \mathrm{~V}$ & $0.81 \mathrm{~V}$ & 33 \\
HC-900 & $0.95 \mathrm{~V}$ & $0.80 \mathrm{~V}$ & $/$ \\
N-CSs & $0.85 \mathrm{~V}$ & $0.81 \mathrm{~V}$ & $/$ \\
GWS180M800 & $1.01 \mathrm{~V}$ & $0.82 \mathrm{~V}$ & This work \\
\hline
\end{tabular}




\section{Experimental Section}

\subsection{Materials}

Green walnut peel was collected in Linfen, Shanxi Province, China. Melamine can be used directly, which is an analytical grade provided by Sinopharm Chemical (Shanghai, China) Co., Ltd.

\subsection{Materials Synthesis}

Firstly, the green walnut peel is cut into $1 \times 1 \mathrm{~cm}$ squares, rinsed with deionized water repeatedly, and dried in a constant temperature drying oven at $70{ }^{\circ} \mathrm{C}$ for $48 \mathrm{~h}$ to obtain dehydrated green walnut peels. It is then crushed with a crusher at 32,000 r/min uniform in $10 \mathrm{~min}$ to obtain less than 100 mesh green walnut peel powder, and named GWS precursor (GWS stands for Green walnut skin, the same below). Taken $1 \mathrm{~g}$ of GWS precursor and $5 \mathrm{~g}$ of melamine (mass ratio 1:5), mixed them evenly, transferred them to high-pressure stainless steel $(100 \mathrm{~mL})$ lined with tetrafluoroethylene, and kept them in an oven at $180{ }^{\circ} \mathrm{C}$ for $12 \mathrm{~h}$, and the obtained material was named as GWS180M. Then the samples are transferred to a constant temperature oven at $70{ }^{\circ} \mathrm{C}$ for drying, and then the GWS180MX was placed in a tube furnace under $\mathrm{N}_{2}$ atmosphere. Carbonization is carried out at four given temperatures $\left(700,800,900\right.$, and $100{ }^{\circ} \mathrm{C}$ ) (heating rate is $5{ }^{\circ} \mathrm{C} / \mathrm{min}$, holding time for $4 \mathrm{~h}$ ). The N-doped carbon material of GWS180M-X ( $\mathrm{M}=$ Melamine, $\mathrm{X}$ represents the carbonization temperature $700,800,900$, and $1000{ }^{\circ} \mathrm{C}$ ) was collected at room temperature. All the obtained GWS catalysts were fully ground in a mortar, and soluble impurities were removed by repeated washing with deionized water and absolute ethanol. The cleaned catalysts were dried in an oven at $60{ }^{\circ} \mathrm{C}$.

\subsection{Structural Characterization}

The surface morphology and structure of all samples are measured by a $10 \mathrm{KV}$ field emission scanning electron microscope (SEM, JEOL JSM-7500F, Tokyo, Japan) and a 200 KV transmission electron microscope (TEM, JEOL JEM-2100, Tokyo, Japan). X-ray powder diffraction (XRD) is used to characterize the crystal structure of the catalyst with $\mathrm{Cu}-\mathrm{K} \alpha$ radiation in the range of $2 \theta\left(10^{\circ}-80^{\circ}\right)$ with a scan rate of $5^{\circ} / \mathrm{min}$. The AMICUS electron spectrometer on SHIMADZU recorded X-ray photoelectron spectroscopy (XPS) using $300 \mathrm{~W}$ Al K $\alpha$ radiation. The electrochemical performance of all catalysts were tested by the electrochemical workstation (Autolab).

\section{Conclusions}

In short, a new type of porous N-doped carbon material can be easily obtained from waste walnut hulls through simple activation and carbonization processes. In this process, using waste walnut hulls as free raw materials has economic and environmental benefits. The resulting material exhibits high electrochemical performance for ORR due to the large surface area and pore structure, as well as isomer doping and abundant defects. The half-wave potential of GWS180M800 after activation and doping with organic pores was greatly increased from 0.70 to $0.82 \mathrm{~V}$, and it showed better stability and methanol resistance than $20 \mathrm{wt} \% \mathrm{Pt} / \mathrm{C}$. This work provides a new strategy and method for exploring the use of low-cost local biomass materials to produce high value-added free-metal biomass carbon ORR catalysts.

Supplementary Materials: The following are available online, Table S1: The content of $\mathrm{C}, \mathrm{N}$, and O elements and N configuration calculated of GWS800, GWS180M700, GWS180M800, GWS180M900, and GWS800M1000 from elemental analysis and XPS.

Author Contributions: Conceptualization, Y.Z. and J.H.; methodology, Y.Z. and J.H.; validation, Y.Z. and J.H.; formal analysis, J.H.; investigation, Y.Z. and J.H.; resources, J.H.; data curation, Y.Z. and L.Y.; writing—original draft preparation, Y.Z.; writing—review and editing, J.H.; visualization, Y.Z. and J.H.; supervision, J.H.; project administration, Y.Z.; funding acquisition, J.H. All authors have read and agreed to the published version of the manuscript. 
Funding: This research was funded by the Applied and Basic Research Program of Shanxi Province (No. 201901D111290), the Science and Technology Innovation Project of Shanxi Province (No. 20191017) and the Open Project of Extreme Optics Collaborative Innovation Center of Shanxi University Coconstructed by the Ministry of Education and Shanxi Province (No. KF2020004).

Institutional Review Board Statement: Not applicable.

Informed Consent Statement: Not applicable.

Data Availability Statement: Not applicable.

Acknowledgments: We thank the Laboratory for Microstructures of Shanghai University.

Conflicts of Interest: The authors declare no conflict of interest.

Sample Availability: Samples of the compounds are available from the authors.

\section{References}

1. Katsounaros, I.; Cherevko, S.; Zeradjanin, A.R.; Mayrhofer, K.J.J. Oxygen electrochemistry as a cornerstone for sustainable energy conversion. Angew. Chem. Int. Ed. 2014, 53, 102. [CrossRef]

2. $\quad \mathrm{Wu}$, K.H.; Wang, D.W.; Zong, X.; Zhang, B.S.; Liu, Y.F.; Gentle, I.R.; Su, D.S. Functions in cooperation for enhanced oxygen reduction reaction: The independent roles of oxygen and nitrogen sites in metal-free nanocarbon and their functional synergy. J. Mater. Chem. A 2017, 5, 3239. [CrossRef]

3. Service, R.F. Cellulosic ethanol: Biofuel researchers prepare to reap a new harvest. Science 2007, 315, 1488. [CrossRef] [PubMed]

4. Fu, P.; Zhou, L.H.; Sun, L.H.; Huang, B.H.; Yuan, Y. Nitrogen-doped porous activated carbon derived from cocoon silk as a highly efficient metal-free electrocatalyst for the oxygen reduction reaction. Rsc Adv. 2017, 7, 13383-13389. [CrossRef]

5. Tao, H.C.; Yan, C.; Robertson, A.W.; Gao, Y.G.; Ding, J.J.; Zhang, Y.Q.; Ma, T.; Sun, Z.Y. N-Doping of graphene oxide at low temperature for the oxygen reduction reaction. Chem. Commun. 2017, 53, 873. [CrossRef] [PubMed]

6. Lee, T.; Jeon, E.K.; Kim, B.S. Mussel-inspired nitrogen-doped graphene nanosheet supported manganese oxide nanowires as highly efficient electrocatalysts for oxygen reduction reaction. J. Mater. Chem. A 2014, 2, 6167. [CrossRef]

7. Arenz, M.; Mayrhofer, K.J.J.; Stamenkovic, V.; Blizanac, B.B.; Tomoyuki, T.; Ross, P.N.; Markovic, N.M. The effect of the particle size on the kinetics of CO electrooxidation on high surface area Pt catalysts. J. Am. Chem. Soc. 2005, 127, 6819. [CrossRef]

8. Shah, S.S.A.; Najam, T.; Molochas, C.; Nazir, M.A.; Brouzgou, A.; Javed, M.S.; Rehman, A.u.; Tsiakaras, P. Nanostructure Engineering of Metal-Organic Derived Frameworks: Cobalt Phosphide Embedded in Carbon Nanotubes as an Efficient ORR Catalyst. Molecules 2021, 26, 6672. [CrossRef] [PubMed]

9. Zhang, J.; Shi, Q.Q.; Zhang, C.L.; Xu, J.T.; Zhai, B.; Zhang, B. Adsorption of neutral red onto mn-impregnated activated carbons prepared from typha orientalis. Bioresour. Technol. 2008, 99, 8974. [CrossRef]

10. Zhou, Y.; Umasankar, Y.; Ramasamy, R.P. Laccase-TiO2 Nanoconjugates as Catalysts for Oxygen Reduction Reaction in Biocathodes. J. Electrochem. Soc. 2015, 162, H911-H917. [CrossRef]

11. Hudak, N.S.; Gallaway, J.W.; Barton, S.C. Mediated Biocatalytic Cathodes Operating on Gas-Phase Air and Oxygen in Fuel Cells. J. Electrochem. Soc. 2009, 156, B9-B15. [CrossRef]

12. Jahan, M.; Bao, Q.; Loh, K.P. Electrocatalytically active graphene-porphyrin MOF composite for oxygen reduction reaction. J. Am. Chem Soc. 2012, 134, 6707-6713. [CrossRef]

13. Sravani, B.; Raghavendra, P.; Chandrasekhar, Y.; Reddy, Y.V.M.; Sivasubramanian, R.; Venkateswarlu, K.; Madhavi, G.; Sarma, L.S. Immobilization of platinum-cobalt and platinum-nickel bimetallic nanoparticles on pomegranate peel extract-treated reduced graphene oxide as electrocatalysts for oxygen reduction reaction. Int. J. Hydrog. Energy 2020, 45, 7680-7690. [CrossRef]

14. Venkateswarlu, K. Ashes from organic waste as reagents in synthetic chemistry: A review. Environ. Chem. Lett. 2021, 19, 3887-3950. [CrossRef]

15. Naidu, B.R.; Lakshmidevi, J.; Naik, B.S.S.; Venkateswarlu, K. Water extract of pomegranate ash as waste-originated biorenewable catalyst for the novel synthesis of chiral tert-butanesulfinyl aldimines in water. Mol. Catal. 2021, 511, 111719. [CrossRef]

16. Boruah, P.R.; Ali, A.A.; Saikia, B.; Sarma, D. A novel green protocol for ligand free Suzuki-Miyaura cross-coupling reactions in WEB at room temperature. Green Chem. 2015, 17, 1442-1445. [CrossRef]

17. Godoi, M.; Leitemberger, A.; Correa Bohs, L.M.; Silveira, M.V.; Rafiq, L.; Montes D'Oca, M.G. Rice straw ash extract, an efficient solvent for regioselective hydrothiolation of alkynes. Environ. Chem. Lett. 2019, 17, 1441-1446. [CrossRef]

18. Su, D.S.; Zhang, J.; Frank, B.; Thomas, A.; Wang, X.C.; Paraknowitsch, J.; Schlogl, R. Metal-Free Heterogeneous Catalysis for Sustainable Chemistry. ChemSusChem 2010, 3, 169-180. [CrossRef] [PubMed]

19. Zhou, L.H.; Fu, P.; Cai, X.X.; Zhou, S.G.; Yuan, Y. Naturally derived carbon nanofibers as sustainable electrocatalysts for microbial energy harvesting: A new application of spider silk. Appl. Catal. B 2016, 188, 31. [CrossRef]

20. Nie, Y.; Li, L.; Wei, Z. Recent advancements in Pt and Pt-free catalysts for oxygen reduction reaction. Chem. Soc. Rev. 2015, 44, 2168. [CrossRef] [PubMed]

21. Zhao, Z.H.; Li, M.T.; Zhang, L.P.; Dai, L.M.; Xia, Z.H. Design principles for heteroatom-doped carbon nanomaterials as highly efficient catalysts for fuel cells and metal-air batteries. Adv. Mater. 2015, 27, 6834. [CrossRef] [PubMed] 
22. Wang, X.X.; Xu, X.X.; Feng, Z.M.; Huo, Y.Q.; Bian, L.J. Loading of cluster-based coordination compound on biomass derived N-doped mesoporous carbon matrix: A bifunctional electrocatalyst for overall water splitting. ACS Sustain. Chem. Eng. 2018, 6, 10282. [CrossRef]

23. Liang, C.; Liang, S.; Xia, Y.; Gan, Y.P.; Fang, L.B.; Jiang, Y.Z.; Tao, X.Y.; Huang, H.; Zhang, J.; Zhang, W.K. Synthesis of hierarchical porous carbon from metal carbonates towards high-performance lithium storage. Green Chem. 2018, 20, 1484. [CrossRef]

24. Han, C.; Chen, Z. The mechanism study of oxygen reduction reaction (ORR) on non-equivalent $\mathrm{P}, \mathrm{N}$ co-doped graphene. Appl. Surf. Sci. 2020, 511, 145382. [CrossRef]

25. Morozan, A.; Jousselme, B.; Palacin, S. Low-platinum and platinum-free catalysts for the oxygen reduction reaction at fuel cell cathodes. Energy Environ. Sci. 2011, 4, 1238-1254. [CrossRef]

26. Liu, W.J.; Jiang, H.; Yu, H.Q. Emerging applications of biochar-based materials for energy storage and conversion. Energy Environ. Sci. 2019, 12, 1751-1779. [CrossRef]

27. Paulus, U.A.; Schmidt, T.J.; Gasteiger, H.A.; Behm, R.J. Oxygen reduction on a high-surface area Pt/Vulcan carbon catalyst: A thin-film rotating ring-disk electrode study. J. Electroanal. Chem. 2001, 495, 134. [CrossRef]

28. Duan, X.; Ao, Z.; Sun, H.; Indrawirawan, S.; Wang, Y.; Kang, J.; Liang, F.; Zhu, Z.H.; Wang, S. Nitrogen-doped graphene for generation and evolution of reactive radicals by metal-free catalysis. ACS Appl. Mater. Interfaces 2015, 7, 4169-4178. [CrossRef]

29. Unni, S.M.; Devulapally, S.; Karjule, N.; Kurungot, S. Graphene enriched with pyrrolic coordination of the doped nitrogen as an efficient metal-free electrocatalyst for oxygen reduction. J. Mater. Chem. 2012, 22, 23506-23513. [CrossRef]

30. Mulyadi, A.; Zhang, Z.; Dutzer, M.; Liu, W.; Deng, Y.L. Facile approach for synthesis of doped carbon electrocatalyst from cellulose nanofibrils toward high-performance metal-free oxygen reduction and hydrogen evolution. Nano Energy 2017, 32, 336-346. [CrossRef]

31. Konwar, L.J.; Sugano, Y.; Chutia, R.S.; Shchukarev, A.; Maki-Arvela, P.; Kataki, R.; Mikkola, J.P. Sustainable synthesis of N and P co-doped porous amorphous carbon using oil seed processing wastes. Mater. Lett. 2016, 173, 145-148. [CrossRef]

32. Guo, C.; Liao, W.; Li, Z.; Sun, L.; Chen, C. Easy conversion of protein-rich enoki mushroom biomass to a nitrogen-doped carbon nanomaterial as a promising metal-free catalyst for oxygen reduction reaction. Nanoscale 2015, 7, 15990-15998. [CrossRef] [PubMed]

33. Zhou, H.; Zhang, J.; Zhu, J.W.; Liu, Z.Y.; Zhang, C.T.; Mu, S.C. A self-template and KOH activation co-coupling strategy to synthesize ultrahigh surface area nitrogen-doped porous graphene for oxygen reduction. RSC Adv. 2016, 6, 73292-73300. [CrossRef]

34. Lai, L.; Potts, J.R.; Zhan, D.; Wang, L.; Poh, C.K.; Tang, C.; Gong, H.; Shen, Z.; Lin, J.; Ruoff, R.S. Exploration of the active center structure of nitrogen-doped graphene-based catalysts for oxygen reduction reaction. Energy Environ. Sci. 2012, 5, 7936-7942. [CrossRef]

35. Li, J.M.; Wang, W.; Wang, F.X.; Kang, Y.M.; Tan, T.; Lei, Z.Q. Astragali Radix-derived nitrogen-doped porous carbon: An efficient electrocatalyst for the oxygen reduction reaction. Int. J. Hydrog. Energy 2018, 43, 551-561. [CrossRef]

36. Shen, W.Z.; Fan, W.B. Nitrogen-containing porous carbons: Synthesis and application. J. Mater. Chem. A 2013, 1,999. [CrossRef]

37. Rao, C.V.; Cabrera, C.R.; Ishikawa, Y. In Search of the Active Site in Nitrogen-Doped Carbon Nanotube Electrodes for the Oxygen Reduction Reaction. J. Phys. Chem. Lett. 2010, 1, 2622-2627. [CrossRef]

38. Favaro, M.; Carraro, F.; Cattelan, M.; Colazzo, L.; Durante, C.; Sambi, M. Multiple doping of graphene oxide foams and quantum dots: New switchable systems for oxygen reduction and water remediation. J. Mater. Chem. A 2015, 3, 14334-14347. [CrossRef]

39. Liu, Y.; Hu, M.; Xu, W.; Wu, X.; Jiang, J. Catalytically Active Carbon From Cattail Fibers for Electrochemical Reduction Reaction. Front. Chem. 2019, 7, 786. [CrossRef]

40. Huang, B.B.; Liu, Y.C.; Guo, Q.; Fang, Y.X.; Titirici, M.M.; Wang, X.C.; Xie, Z.L. Porous carbon nanosheets from biological nucleobase precursor as efficient $\mathrm{pH}$-independent oxygen reduction electrocatalyst. Carbon 2020, 156, 179-186. [CrossRef]

41. Tang, Z.J.; Pei, Z.X.; Wang, Z.F.; Li, H.F.; Zeng, J.; Ruan, Z.H.; Huang, Y.; Zhu, M.S.; Xue, Q.; Yu, J.; et al. Highly anisotropic, multichannel wood carbon with optimized heteroatom doping for supercapacitor and oxygen reduction reaction. Carbon 2018, 130, 532-543. [CrossRef]

42. Ye, W.Y.; Tang, J.H.; Wang, Y.J.; Cai, X.X.; Liu, H.W.; Lin, J.Y.; Van der Bruggen, B.; Zhou, S.G. Hierarchically structured carbon materials derived from lotus leaves as efficient electrocatalyst for microbial energy harvesting. Sci. Total Environ. 2019, 666, 865-874. [CrossRef] [PubMed]

43. Chen, P.; Wang, L.K.; Wang, G.; Gao, M.R.; Ge, J.; Yuan, W.J.; Shen, Y.H.; Xie, A.J.; Yu, S.H. Nitrogen-doped nanoporous carbon nanosheets derived from plant biomass: An efficient catalyst for oxygen reduction reaction. Energy Environ. Sci. 2014, 7, 4095-4103. [CrossRef] 